\section{THE INSTITUTION OF NAVAL} ARCHITECTS.

THE annual meeting of the Institution of Naval Architects opened on Wednesday, March 27, at the Royal Society of Arts, and extended over Thursday and Friday. The annual gold medal of the institution was presented to Prof. E. G. Colker for his paper on the determination of stresses by the photo-elastic method. Premiums were also awarded to Mr. C. E. Inglis and Mr. J. Montgomerie for papers read at the last spring meeting. The first award of a scholarship of $200 l$. per annum from the I85I Exhibition Commissioners has been made to Mr. Arthur Cannon on the recommendation of the council of the institution. Mr. Cannon is pursuing a course of research work at Glasgow University in problems connected with the rolling of ships, and read a preliminary paper at this meeting on the effect of an internal free fluid upon the initial stability.

The president (the Marquis of Bristol) delivered an address in which he directed attention to the record in shipbuilding achieved during the past year. Merchant shipping launched in the United Kingdom advanced by $5^{8}$ per cent., and warships by $7^{1}$ per cent., as compared with the previous year. There is no lack of orders at present, but the labour unrest threatens to arrest many of the benefits which should follow on the recent revival of trade.

Admiral Sir Reginald Custance, in his paper on some military principles which bear on warship design, advocated the development of fire effect to the fullest extent possible. The decline in the value of armour and its possible reduction, coupled with the increased range and power of modern guns, are the changed conditions which may enable a return to be made to this old and well-tried principle. There is reason to doubt whether batteries of comparatively few large guns form the most effective armament. The admiral's views that armour, speed, and size of guns should be sacrificed in order to secure more guns were strongly contested by several speakers.

A paper on the law of comparison for surface friction and eddy-making resistances in fluids was read by Dr. T. E. Stanton. The prediction of wavemaking resistance from experiments on models according to Froude's law of comparison is usually carefully treated by authorities on naval architecture, but there does not appear to be any suggestion of a similar treatment of the surface friction and eddymaking problem. Prof. Osborne Reynolds showed nearly thirty years ago that, in two pipes in which the lengths, diameters, and surface irregularities were in a given constant ratio to each other, if the velocities were made in the inverse of this ratio, the total frictional force was the same for each pipe. Lord Ravleigh has shown that, in cases where there is no resistance due to surface waves and the velocity is not high enough to produce cavitation, the resistance per unit area can be expressed by

$$
\mathrm{R}=\frac{1}{2} \rho \mathrm{V}^{2} k \text {, }
$$

where $k$ is an expression depending solely on $\rho \frac{v l}{\mu}$, $\mu$ being the coefficient of viscosity of the fluid and $\rho$ its density. This law of comparison applies equally well to cases in which the resistance is made up partly of surface friction and partly of eddy making. Experimental verifications of the truth of this relation have been obtained at the National Physical Laboratory in two cases, viz., the determination of the frictional resistance of two different fluids (air and water) on the same surface, and the total resistance in water of models of a dirigible balloon to different scales. The latter tests are of particular interest. NO. 22 I 4 , VOL. 89 ]
Two models of the same dirigible to different scales were towed in the experimental tank and their resistances measured. If the law of comparison holds, their resistances will be equal for the same value of $v l$, and this was found to be the case very closely. It thus becomes possible to estimate the resistance in air of a dirigible balloon by experiments in which a model is towed under water. Obviously the same method is applicable to torpedoes and submarines.

In the course of the last seven years considerable data have been collected regarding the rolling of Irish lightships. The results were summarised in a paper read by Messrs. George Idle and G. S. Baker. (a) The greatest rolling amplitudes are attained by the old ships, wooden or composite, having double bilge logs. These ships have generally small initial stability and a low metacentre, and show that the metacentric height does not by itself give any indication of the ship's probable behaviour in a heavy sea. (b) Large amplitudes are reached when the sea is brealking or confused and when the waves are advancing on the bows or quarters. Maximum amplitudes have been recorded when the ship has been nearly head to the advancing wave. The differences in amplitude of "head to" and "beam to" positions in heavy swells averaged r6 to 20 degrees for the single oscillation in favour of the latter, suggesting that there are causes productive of heavy rolling other than mere assonance between the ship and the wave. (c) The greatest angle of heel is always away from the advancing wave, no matter what may be the direction and force of the wind. (d) When the bilge keels are efficient the ship's normal period of oscillation is increased by one up to three seconds, sometimes more. The amplitudes of roll are generally moderate in this increased period. There is apparently an attempt on the part of the wave to bring the ship to its own period, and the function of the bilge keel is evident in the fact that it prevents assonance between the ship and the wave. It may be safely asserted that without bilge keels these small vessels could scarcely live in the seas to which they are sometimes exposed. A valuable series of experiments was undertaken last year at the William Froude National Tank on a model of an actual ship built for the Commissioners of Irish Lights. The experiments have been taken beyond the immediate requirements of the commissioners with the view of testing the ordinary equation for the decrement of roll per single swing of the ship, viz. :

$$
-\delta \theta=a \theta+b \theta^{2}
$$

$\theta$ being the mean angle of swing port and starboard, and $a$ and $b$ coefficients which depend, the former on wave-making resistance and the latter on friction and head resistance. The results show discrepancies, and that there should probably be a term in $\theta^{3}$ if the bilge keel is sufficiently near the water line.

The propulsion of modern vessels is developing along various lines, viz. internal-combustion engines, the steam turbine with speed-reduction appliances interposed between the turbines and the propeller, and in steam generation oil fuel finds many advocates. Papers on the Diesel-engined sea-going vessel Selandia and on gas power for ship propulsion were read respectively by Messrs. W. I. Knudson and A. C. Holzapfel, and Prof. J. H. Biles read a paper on the geared turbine Channel steamers, Normannia and Hautonia, in which the relative merits are discussed of mechanical gearing, electrical transmission, and hydraulic transmission for speed reduction between the turbine and the propeller shafts. The maximum efficiency of electrical transmission is about 90 per cent.; this method may be useful in cases where a great range of speed at high efficiency would 
be advantageous. Dr. Föttinger's system of hydraulic transmission gives an efficiency of about go per cent. at full speed. Both electrical and hydraulic systems admit of very large powers astern without separate prime movers. Helical gears with machine-cut teeth (made by Messrs. Parsons) were fitted to the steamers forming the subject of the paper. The loss in this gearing amounts to $\mathrm{I}^{\circ} 5$ per cent. only. There is practically no noise; a slight whistling sound can be heard by listening carefully when in the passenger quarters. There are no vibrations or trepidations. Sir Charles Parsons stated that most of the $1^{*} 5$ per cent. waste occurred in the pinion bearings. There is no wear in the teeth, the oil film apparently being preserved unbroken. Dr. Föttinger raised the point of the limit of power which could be transmitted; his hydraulic gear was being fitted for very large powers. Mechanical gearing has been used for comparatively low powers up to the present, but no doubt can be developed to a much greater extent.

The discussion of the previous day on $\mathrm{Mr}$. W. I. Knudson's paper on the Selandia provoked further comments on the Diesel engine from speakers in the discussion on Prof Bile's paper. The height of Diesel engines for a warship would be much greater than that of geared turbines; with the oil engines the most vulnerable parts of the machinery might be above the water line. The Selandia was reported at the meeting to be making good progress on her first voyage, and was passing through the Red Sea at above eleven knots.

In all seventeen papers were read and discussed at the meeting; the limitations of space have forbidden reference being made here to other than the more important papers.

\section{THE INTERNATIONAL SMOKE ABATE- MENT EXHIBITION.}

THE remarkably clear atmosphere which has been observed in many industrial centres during the coal strike has afforded an excellent object-lesson in smolke abatement. It should emphasise the desirability of making these conditions permanent. That the removal of smoke comes well within the range of practical achievement has been amply demonstrated by the International Smoke Abatement Exhibition which has just been held under the auspices of the London Coal Smoke Abatement Society. In the official catalogue of the exhibition we find references not only to the exhibits of smoke-saving and smokepreventing appliances, but to practical demonstrations of their use. The exhibition has further provided opportunity for a series of excellent lectures and addresses by well-known authorities, which include men of science, engineers, and manufacturers of English, German, and American nationality.

The exhibits may be divided into two categories, those which are devised for burning coal or partially coked material smokelessly, and those which replace the solid fuel by oil, gas, or electricity.

Anyone who may have watched the cookery demonstrations with gas cookers or observed the great improvement in the appearance of the various gas fires, or examined the electrical heating apparatus for domestic use, must have been impressed with the great advantage in cleanliness, convenience, and efficiency which these methods of heating possess over the coal fire. Indeed, it is impossible not to carry away the conviction that in the use of gas and electricity for heating and cooking, lies our future hope of salvation from the smoke fiend. The chief obstacle at present is their cost. Yet in spite of the high price of gas as compared with coal of the same calorific value, it is interesting to learn that during the last ten years there has been an increase of nearly two million gas cookers in the United Kingdom, whilst the total number of gas heating and cooking appliances installed by the London gas companies in Igro reached $1,300,000$.

This is a matter of considerable importance when it is remembered that the domestic hearth not only turns out by far the greater proportion of soot on the coal burnt, but soot of that particularly obnoxious quality which, by its high content of tar, is the most adhesive and permanent.

We have not space to refer to the numerous papers read at the conference, but must refer our readers to the small volume which has been issued by the Coal Smoke Abatement Society, 25 Victoria Street, Westminster, price 2s. 6d., which is well worth perusal by those who are interested in the various phases of the smoke question.

The papers may be divided into those dealing with (I) the causes, (2) the cure, and (3) the effects of smoke. Among the last, valuable information was contributed by Sir A. Church and $\mathrm{Mr}$. N. Heaton on the important subject of the disintegration of building stone and the destruction of mural decoration by atmospheric sulphuric acid arising from burning coal, and experimental evidence showed that the stonework of ancient historic buildings was being slowly corroded. Dr. Rideal, who dealt with the effects on metal work, found that the rust on a roof girder of Charing Cross Station which collapsed in I905 contained $4^{2} 25$ per cent. of sulphuric acid, equal to nearly 9 per cent. of ferrous sulphate. The effects on vegetation are even more disastrous, and striking experimental results were recorded by $\mathrm{Mr}$. W. J. Bean, assistant curator of Kew Gardens, and $\mathrm{Mr}$. A. G. Ruston, of the Agricultural Department of the University of Leeds. The effects on health were discussed by Mr. W. B. Smith, chairman of the Air Purification Committee of the Glasgow Corporation, who gave statistics proving the high mortality from bronchial diseases during town fogs.

Though there has been some repetition of old arguments, opinions, and facts, these are subjects which cannot be too frequently dinned into the ears of an indifferent public in the hope that an echo of them may ultimately reach the local authorities and rouse them to a sense of their duty.

It is satisfactory, however, to learn from Mr. Lempfert, of the Meteorological Office, and Mr. J. B. C. Kershaw that matters are slowly improving. The number of hours of bright sunshine in the year in industrial centres, compared with certain country places, has steadily increased, showing that either the country stations are making more smoke or the towns less. The author of the paper, Mr. Lempfert, takes the latter and more sanguine view. He makes the significant remark that "the great difference between the figures for winter and those for summer suggests that domestic smoke rather than factory, smoke is mainly responsible for the loss of sunshine." Now legislation in this country has not yet ventured to invade the sanctity of the domestic hearth, yet it
is proved beyond question that it is the worst offender. Mr. Nicholson, smoke inspector for Sheffield, asks, with perfect justification, "Why should our domestic fireplaces be allowed to create an unnecessary nuisance any more than any other fireplace or furnace?" The answer is: provide cheap gas and electricity. The splendid combined exhibit of the gas companies and of the London electric supply and other manufacturers of electric appliances leaves little to be desired in the apparatus designed to utilise these two forms of energy. 